\title{
Democracia y Ciudadanía en América Latina
}

Por Pablo Ronchi Talsky ${ }^{1}$

\section{Resumen}

¿Por qué es importante recuperar el concepto de democracia en América Latina? ¿Cuál ha sido el rendimiento de las democracias latinoamericanas desde la década del 80 en la reducción de las desigualdades? ¿Qué sucede con la idea de ciudadanía y participación? ¿Cuáles son los obstáculos para la profundización democrática? Este ensayo pretende introducir algunas perspectivas para analizar estas interrogantes, concentrando la atención en el daño que han hecho las tradiciones del Norte Clobal y el neoliberalismo en la construcción de una idea de democracia capaz de movilizar a la ciudadanía hacia proyectos políticos hegemónicos y soberanos que reduzcan la desigualdad y promuevan un paradigma del bienestar que dé respuesta a las necesidades e intereses de los pueblos latinoamericanos.

Palabras clave: Democracia, participación, ciudadanía, América Latina.

\section{Introducción}

Si bien América Latina es un territorio tremendamente extenso, nutrido de diversidad cultural y de los más variados paisajes, comparte el desafío (y la preocupación) por consolidar los procesos democráticos en la mayoría de los territorios o, en todo caso, la necesidad de profundizarlos a través de un mayor involucramiento de los y las ciudadanas en las grandes decisiones. Una convicción que se basa en posicionar el ejercicio de la participación en el campo de la disputa contra-hegemónica frente al modelo neoliberal, lesivo para la ciudadanía, que -impuesto a fuerza de represión sistematizada- ha acompañado las olas democratizantes de los 80's, permeando la gran mayoría de las lógicas político-institucionales, dejando como saldo los mayores índices de desigualdad del planeta.

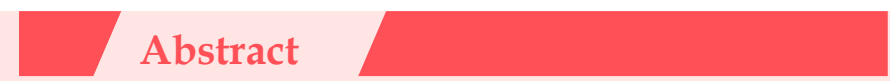

Why is it important to recover the concept of democracy in Latin America? What has been the performance of Latin American democracies since the 1980 s in reducing inequalities? What happens to the idea of citizenship and participation? What are the obstacles to democratic deepening? This essay aims to introduce some perspectives to analyse these questions,focusing attention on the damage done by the traditions of the Clobal North and neoliberalism in the construction of an idea of democracy, capable of mobilizing the citizenship towards hegemonic and sovereign political projects that reduce Inequality and promote a welfare paradigm that responds to the needs and interests of the Latin American peoples.

Key words: Democracy, participation, citizenship, Latin America. .

Es importante recuperar un concepto tan antiguo como el de democracia, porque se trata de un ideal joven en Latinoamérica, de evoluciones cíclicas que busca reformularse a partir de una identidad (o de diversas identidades) local que, nutriéndose de tradiciones heredadas del período de segunda postguerra, logre

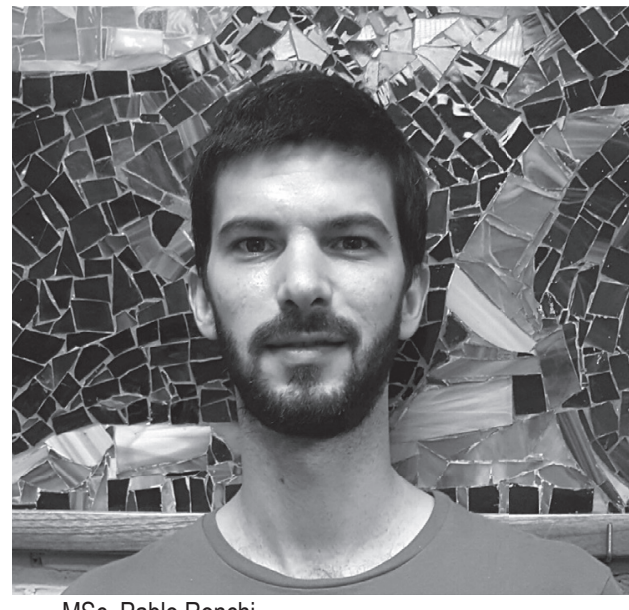

MSc. Pablo Ronchi. consolidarse como un sistema de derechos que opere de plataforma para construir un paradigma de bienestar inclusivo, soberano y participativo en América Latina.

1 Maestría en Estudios Internacionales de Paz, Conflicto y Desarrollo, Universitat Jaume I, España; Licenciado en Administración, Universidad Nacional del Litoral, Argentina; Cooperante en IMLK-UPOLI (2017). pabloronchi@hotmail.com 
Por otra parte, se plantea el desafío de mantener viva la memoria de una de las etapas más oscuras y dolorosas de la historia latinoamericana, caracterizada por una oleada de dictaduras cívicomilitares, entre finales de la década del $60^{\prime}$ y principios de la del $80^{\prime}$. Debatir sobre la cuestión democrática, contribuye a mantener vigente el repudio a cualquier tipo de expresión autoritaria del poder y, en especial, a aquellas que han secuestrado las estructuras de los Estados para reprimir a sus propios pueblos.

Sin embargo, la consolidación de la democracia electoral en toda la región ha venido acompañada de un proceso de decepción ciudadana respecto al rendimiento de los modelos democráticos hacia los inicios del siglo XXI, según ha demostrado el informe sobre la democracia en América Latina Nuestra Democracia desarrollado por el PNUD y la OEA en $2010 .^{2}$

En los últimos años tampoco se observa una mejora en este sentido, de hecho el informe 2016 del Latinobarómetro, da cuenta de una caída sostenida desde el 2010 en el apoyo a la democracia, alcanzando uno de sus picos más bajos en $2016 .^{3}$

No obstante, hasta nuestros días, la democracia parece ser la mejor herramienta que hemos encontrado para afrontar los grandes desafíos de la organización social, la puja de intereses y las tensiones que éstos generan. Aunque es evidente que como proyecto es generalmente difuso y perfectible.

En ese camino, se hace necesario profundizar, sin ánimo de exhaustividad, en algunas contradicciones que atraviesan las democracias de la región, indagar en las dificultades y los desafíos pendientes, así como discutir los marcos epistemológicos desde donde se articulan los saberes.

\section{Triple crisis en la explicación de la democracia. Una relectura desde los estudios para la paz}

La compleja tarea de repensar la democracia presenta una primera característica, tan esencial como innegable, y es que no existe un único modo de concebirla. Esta sencilla idea echa por tierra la pretensión homogeneizante del proyecto demócrata liberal occidental y es, a su vez, consistente con la evidente dificultad para establecer un patrón más o menos preciso de tipologías democráticas en América Latina.

Por lo tanto, se puede identificar lo que Boaventura de Sousa Santos ${ }^{4}$ define como la "triple crisis de la explicación democrática", para analizarla a partir de los aportes de los estudios para la paz.

En primer lugar, existe una "crisis en el marco estructural de explicación de la posibilidad de la democrática", que Santos toma de Barrington Moore ${ }^{5}$ y se puede interpretar como la posibilidad de consecución de las condiciones mínimas estructurales para alcanzar y sostener un escenario de confrontación pacífica de intereses.

Este enfoque tiene estrecha relación con las posibilidades de acceso de las grandes mayorías populares a un cierto bienestar (dimensión distributiva) y a determinados derechos básicos necesarios para generar confianza y decidir -entonces- participar en los procesos políticos, donde la calidad de las instituciones juega un rol determinante.

Entonces, se dispara un interrogante sobre la posibilidad de coexistencia de un sistema de derechos -la democracia- con virtudes redistributivas y el capitalismo -la democracia- en sentido amplio, en sus diferentes fases, con tendencia a la acumulación del capital. 
Concretamente, en Latinoamérica, los proyectos neoliberales, que comenzaran a gestarse impuestos por gobiernos autoritarios bajo el patrocinio de la Secretaría de Estado de loa EE.UU.6, se consolidarían luego con el retorno a la democracia en la década del $80^{\prime}$ y se profundizarían en la siguiente, favoreciendo la agudización de las desigualdades, la exclusión social y la descomposición de la sociedad con una democracia reducida al ejercicio electoral. ${ }^{7}$

Planteada la contradicción, consolidada la crisis que Boaventura de Sousa Santos sintetiza en la paradoja de que "[...] la extensión de la democracia (formal) haya traído consigo una enorme degradación de las prácticas democráticas". 8

En segundo lugar, hay una "crisis de la explicación homogeneizante de la democracia". Esta tensión tiene estrecha relación con lo recién mencionado y se explica en el origen del ideal democrático al que se aspira como horizonte en Latinoamérica. Aquel que surge de los debates del período entreguerras, ${ }^{9}$ buscando dar respuesta -fundamentalmente- a los problemas y necesidades de los países del "Norte Global". ${ }^{10}$

Los estudios para la Paz han generado contribuciones sustanciales en esta línea, especialmente a partir del aporte de los llamados postcolialistas, ${ }^{11}$ que permiten visibilizar algunas de las consecuencias del colonialismo europeo y su repercusión en las problemáticas actuales.

Tal vez lo más significativo en este caso- del enfoque, radica en el reconocimiento de una continuidad en el proceso cultural de dominación colonial y, asociado a esto, la violencia epistémica/simbólica que se ha ejercido sobre los saberes y las construcciones narrativas de los territorios conquistados (luego descolonizados). Proceso que se ha conjugado a partir de la imposición de determinados discursos (políticos, ideológicos, culturales) homogéneos, negando la hibridez de las identidades y culturas latinoamericanas, su interdependencia y el derecho de los conquistados a sus propios sistemas de conocimiento: su derecho a nombrar el mundo con sus propias palabras. ${ }^{12}$

Así, por ejemplo, la tradición liberal de la democracia reduce la discusión sobre las reglas y procedimientos democráticos a la cuestión electoral, imponiendo una exclusiva concepción representativista del sistema político, invisibilizando -e incluso atacandoalternativas de participación de mayor intensidad, disruptivas con el proceso de elección de élites. ${ }^{13}$ De esta manera, se instala la representatividad democrática como único camino viable para afrontar problemas de gran escala, silenciando la diversidad de dinámicas democráticas directas y participativas que operan en diversos contextos comunitarios.

Esto se grafica en el hecho de que las sociedades modernas han sido capaces de desarrollar mecanismos sofisticados y extendidos para garantizar los procesos electorales, destinando una enorme cantidad de recursos de todo tipo. Sin embargo, en general, no se ha movilizado el mismo interés en generar herramientas de participación y control popular de las políticas públicas o, en todo caso, en reconocer y replicar (insititucionalizar) aquellas existentes.

En el mismo sentido, Boaventura de Sousa Santos plantea la forma en que la burocracia se instaló en la teoría sobre la democracia como indispensable, mientras le reconoce -entre otras-

6 Henry Kissinger, Secretario de Estado de Estados Unidos (1973-1977) durante la presidencia de Richard Nixon (1969-1974), ha sido señalado como el autor e ideólogo del Plan Cóndor, una organización clandestina internacional que asesoró y financió a las dictaduras sudamericanas.

7 Borón, Atilio (2005).

8 Santos, Boaventura de Sousa (2004), p. 13.

9 Schumpeter (1942), citado en Santos, Boaventura de Sousa (2004).

10 Norte y Sur Global son conceptos que surgen de los movimientos anti-globalización capitalistas. Parecido a Centro/Periferia. Una metáfora espacial que se utiliza para referirse en ocasiones a un destino común que la globalización capitalista asigna a los países, y en otras, a un Sur y un Norte que se deslocalizan en cada país pero donde el Sur sigue subordinado al Norte. Ver Llistar Bosch (2009).

11 Dussel, E. (2006); Escobar, A. (2003); Mignolo, W. (2005); Omar, S. (2008).

12 Omar, S. (2008) pp. 17-18.

13 Santos, Boaventura de Sousa (2004) 


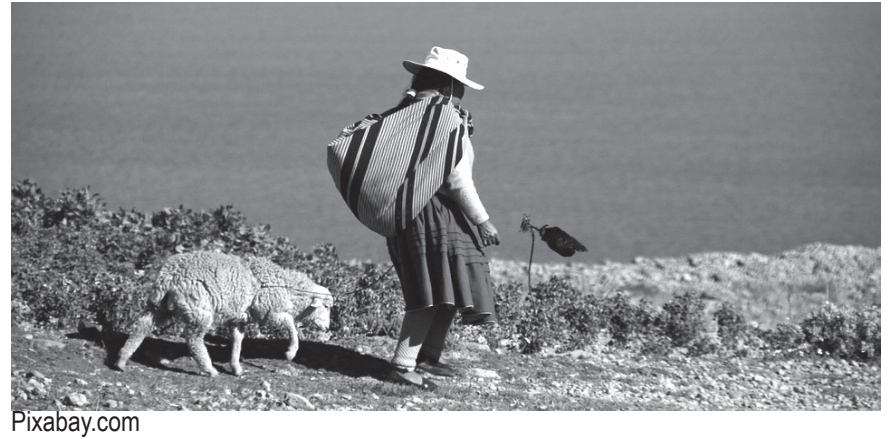

una incapacidad para "lidiar con el conjunto de las informaciones necesarias para la ejecución de políticas complejas en las áreas social, ambiental o cultural" ${ }^{14}$

En tercer lugar, existe "una nueva propensión a examinar la democracia local y la posibilidad de diversas variantes dentro de los Estados nacionales, a partir de la recuperación de tradiciones participativas no visibilizadas en el proceso de construcción de identidades nacionales homogéneas (Anderson, 1991)". ${ }^{15}$

Pero los estudios para la paz, agregan una complejidad complementaria que refiere a la idea de lo glocal y la crisis de los Estados-Nación modernos, como grandes garantes de las democracias, para generar soluciones.

El término "glocal", difundido por el sociólogo alemán Ulrich Beck, ha sido apropiado por los estudios de paz para explicar la tensión entre la potencia homogeneizante de la globalización y las resistencias locales. Esta tensión, en relación a los Estados, podría sintetizarse en las dificultades que estos afrontan por ser demasiado pequeños para atender la complejidad de las problemáticas de escala global y demasiados grandes para ocuparse de las particularidades de las demandas locales.

En esos contextos, donde el Estado no alcanza o no llega, es precisamente donde están surgiendo (o han estado siempre) alternativas de ejercicio ciudadano participativo que incluso, en algunos casos han sido institucionalizadas en virtud de la demanda popular, como el Presupuesto Participativo [PP], una herramienta que hoy se aplica en más de 1500 ciudades del mundo y tiene sus orígenes en Latinoamérica.

\section{Los "peligros" de la participación}

Para introducir esta cuestión, conviene primero analizar quiénes son los y las sujetos de la participación o sujetos de las democracias. Definir al ciudadano o la ciudadana es igualmente una tarea compleja y difícil de consensuar.

Sin embargo, es posible establecer algunas líneas orientativas, entendiendo que cualquier intento por definirlo estará atravesado por un enfoque éticoideológico estructurante.

En esta línea, al igual que sucede con el concepto de democracia, se asume que en el problema de la explicación de la ciudadanía existen tensiones. Al menos una de las que interesa desatacar, se ubica en que la idea de ciudadano o ciudadana estará vinculada al proyecto político que intenta establecerse como hegemónico.

La perspectiva neoliberal promueve $\mathrm{y}$ ha promovido un ciudadano-sujeto de consumo, un enfoque que responde a la paradoja de Boaventura de Sousa Santos planteada anteriormente, donde el campo de ejercicio de la ciudadanía no está en la política sino en el mercado y su pertenencia en el consumo.

El sociólogo y politólogo Atilio Borón, lo explica como un proceso de "desciudadanización" a partir de la aplicación de proyectos neoliberales que, al contrario de acercar a la sociedad civil a los procesos políticos, restringe derechos e incluso favorece la reproducción de clases políticas corruptas. ${ }^{16}$

Esta situación genera una espiral viciosa de desconfianza-alejamiento, otorgándole a la política un sentido perverso y deleznable. En ese marco, la capacidad de profundización democrática, depende en gran medida del lugar que ocupe la participación ciudadana.

Entonces, un ejercicio interesante es preguntarse quiénes pueden oponerse a desarrollar mecanismos que

14 Sabel C. (1999) citado en Santos, Boaventura de Sousa (2004).

15 Santos, Boaventura de Sousa (2004) p. 12.

16 Borón, A. (2005). 
profundicen la cultura participativa y las posibilidades de acceso de las mayorías populares a las grandes definiciones de las políticas públicas. $\mathrm{O}$, dicho de otro modo, indagar en cuáles son las resistencias que podrían explicar el escaso avance en la región hacia lo que Boaventura de Sousa Santos define como democracia de alta intensidad.

En primer lugar, los proyectos neoliberales que tuvieran su auge en las últimas décadas del siglo XX y que han vuelto a aparecer en los últimos años en Latinoamérica, son fuertemente lesivos para la democracia y la participación ciudadana.

No solo porque promueven el individualismo y la maximización del lucro por encima de valores como la solidaridad y la cooperación, sino porque como proyectos políticos han demostrado una concepción de la ciudadanía atomizada, como sujetos pasivos de las políticas públicas, dejando incluso a vastos sectores de la sociedad excluidos de la participación y del acceso a derechos fundamentales para vivir dignamente.

En segundo lugar, el clientelismo, que genera una relación tan compleja como perversa, muchas veces de dependencia entre la ciudadanía y las élites políticas. Por su propia dinámica y volatilidad obstruye la generación de formas genuinas de participación.

En un sentido más amplio, en las últimas dos décadas, se ha producido una actualización de la matriz populista en América Latina, entendido como un fenómeno complejo que presenta una tensión entre elementos democráticos y no democráticos. Como explica Svampa, en estefenómeno"coexiste la crítica del neoliberalismo con el pacto con el gran capital; procesos de democratización con la subordinación de los actores sociales al líder; la apertura a nuevos derechos con la reducción del espacio del pluralismo y la tendencia a la cancelación de las diferencias, entre otros" ${ }^{17}$
En efecto, resulta también interesante -e indispensable- analizar la transformación del papel de los partidos políticos en las últimas décadas, en tanto la ciudadanía ya no se siente representada por estos, sino que, como afirman Albala y Vieira, ${ }_{18}$ "actúa de forma más autónoma al intentar hacer llegar al poder público sus demandas".

Sin embargo, en general, la actuación a través de las organizaciones sociales o movilizaciones espontáneas tampoco han motivado grandes cambios en los sistemas partidistas. Por el contrario, Albala y Vieira advierten que "algunas de las pautas levantadas por estos movimientos son generalmente cooptados por algunos de los partidos políticos". Mientras tanto, los líderes políticos se acercan cada vez más a la figura de intermediarios de obtención de recursos y adhesiones, " (...) sobre bases de intercambios de servicios más que sobre bases programáticas o ideológicas".

En tercer lugar, de acuerdo con el economista y sociólogo Bernardo Kliksberg, en los liderazgos políticos de la región existen grupos que poseen una "visión tecnocrática" de la gestión pública. Esta perspectiva considera a la participación básicamente como una dilación, una pérdida de tiempo innecesaria. ${ }^{19}$

Además, se trata de una visión que, por un lado, significa el temor al riesgo de fiscalización por parte la comunidad de la tarea de los gestores de las políticas y, por otro, posee rasgos descalificativos sobre el grueso del pueblo, por el supuesto desconocimiento técnico, falta de experiencia, de educación, de capacidad o cualquier otro artilugio para eludir la consulta popular, especialmente de los sectores más vulnerables.

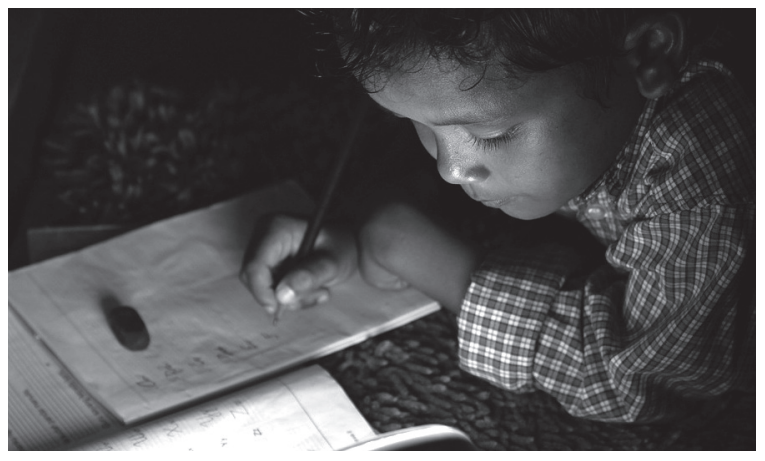

Por último, quienes concentran grandes porciones de poder, suelen considerar a los procesos participativos como un peligro, en función de que suponen la condición de compartir cierta porción de ese privilegio. ${ }^{20}$ 
Los postcolonialistas también han señalado el modo en que la modernidad hegemónica del norte global ha construido una concepción del poder exclusivamente asociado a la noción de "dominación". Esta manera de entender el poder obstruye la posibilidad de desarrollar condiciones favorables a la participación ciudadana y, además, se da en el marco de la promoción del individualismo que atenta contra la formación de colectivos capaces de equilibrar las relaciones de dominación..$^{21}$

\section{Obstácullos y desafíos para la profundización democrática}

Si bien se trata de una tendencia, en los últimos años parece haberse producido un giro restaurador hacia proyectos neoliberales en la región, en algunos casos con tremendas crisis políticas e institucionales (como Honduras, Paraguay, Brasil o Venezuela), cargados de una clara injerencia internacional desestabilizante. A esto se agrega el debilitamiento de los procesos de cooperación entre países latinoamericanos, que habían prometido un regionalismo desafiante en la década anterior, conformando un escenario que, no sólo es lesivo para la democracia, como se ha intentado demostrar, sino que la pone en riesgo.

Sin embargo, tampoco se puede asegurar que las alternativas emergentes en el siglo XXI hayan colmado las expectativas emancipadoras en el marco de la democracia que permitan superar aquella pregunta que planteaba Immanuel Wallerstein a principios de siglo: cómo la democracia se había convertido de una aspiración revolucionaria en el siglo XIX a un slogan vacío de contenido en el siglo XX. ${ }^{22}$

Evidentemente, no cualquier proceso formalmente democrático supone una profundización, es necesario cuestionar permanentemente quiénes son los sujetos de las democracias y quiénes quedan excluidos de ese privilegio. La participación implica -necesariamenteuna fuerte asignación de recursos, no solo monetarios sino institucionales, materiales y simbólicos en general; y es, por lo tanto, en buena parte, una definición política.

En el mismo sentido, es necesario avanzar en debates de fondo de los sistemas políticos latinoamericanos, en el marco de fortalecer las virtudes democráticas: ison los partidos políticos la mejor síntesis de la movilización ciudadana en América Latina?, Pixabay.com ¿Tienen éstos capacidad suficiente para construir hegemonías heterogéneas? ¿Cómo se reparten las posiciones simbólicas en éstas sociedades, quién tiene "derecho" a hablar en nombre del pueblo? Y lo que se sugiere como el debate coyuntural más importante y más urgente en América Latina: ¿cómo se financia la política?

Debatir la financiación de la política es evidentemente un problema escabroso, que genera resistencias, pero que condiciona el acceso de vastos sectores, tanto de la política como de la sociedad en general, a los mecanismos que los sistemas democráticos ofrecen para influir en las grandes decisiones, así como para alcanzar posiciones simbólicas que legitimen el derecho a hablar en nombre del pueblo. No es objeto de este trabajo, pero se trata -como se ha dicho- de un debate central en el camino a la democratización de la democracia y que, además, se vincula con el fenómeno del cabildeo (o lobismo), la corrupción y hasta el crimen organizado.

Paralelo a esto, se debe proponer una discusión sobre el modelo de desarrollo extractivoexportador, que ha sido una tentación irresistible para los gobiernos latinoamericanos en las últimas décadas, independientemente del proyecto político. En primer lugar, porque implica una hipoteca sobre el futuro en términos ambientales; en segundo lugar, porque reactualiza la idea de dependencia, donde es necesario analizar la relación con las nuevas potencias globales emergentes (particularmente China); y en tercer lugar, porque está concentrando un sector importante de la movilización popular de resistencia, especialmente vinculado con los pueblos originarios y las comunidades campesinas, en varios puntos de la región, configurando

21 Dussel, E. (2006). 34-37.

22 Wallerstein, I (2001), citado en Santos, Boaventura de Sousa (2004) p. 9. 
una potente racionalidad política que demanda participación real. ${ }^{23}$

Por supuesto, que es necesario también el fortalecimiento de las instituciones, pero siempre en un sentido democratizante, que facilite el desarrollo de mecanismos de control popular. Los presupuestos participativos son un ejemplo de que esto es posible, pero no es suficiente. La justicia, la seguridad, la educación, la salud, el sistema tributario, deben avanzar hacia el diseño de políticas públicas que acerquen a ciudadanos y ciudadanas a la toma de decisiones, donde las tecnologías de la información y comunicación ofrecen un enorme abanico de posibilidades.

La construcción de hegemonías de alta intensidad democrática, debería traducirse en proyectos capaces de contener diversidad de expresiones, porque las perspectivas y los movimientos feministas, medioambientales o del buen vivir, por ejemplo, son las que están operando en este momento en la vanguardia del paradigma de bienestar y que, junto con muchos procesos participativos que funcionan en el Sur Global, pueden contribuir a construir una identidad hegemónica y heterogénea.

Finalmente, es necesario desarrollar la flexibilidad suficiente para comprender que las identidades colectivas son dinámicas, se transforman y que, por lo tanto, requieren de actualización, renovación de los liderazgos y debate permanente. Es por eso que, la profundización democrática no es un fin en sí mismo, el camino hacia ese horizonte debe ser también profundamente democrático, desde los saberes, las necesidades y los problemas definidos por los ciudadanos y ciudadanas latinoamericanas.

\section{Bibliografía}

Albala, A. y Vieira S.M. (2014). ¿Crisis de los partidos en América latina? El papel de los partidos políticos latinoamericanos en el escenario reciente. Revista de Ciencia Política, 52(1), 145-170. Recuperado de http:/ / www.redalyc.org/pdf/645/64532006006. pdf

Borón, A. (2005). Estado, Capitalismo y Democracia en América Latina. Buenos Aires, Argentina, Clacso.

Dussel, E. (2006). 20 tesis de política. México, DF. Siglo XXI. Escobar, A (2003). Mundos y conocimientos de otro modo. Revista Tabula Rasa, (1), 51-86. Recuperado de http://www.revistatabularasa.org/numero-1/ escobar.pdf.

Kliksberg, B. (2007). ¿Cómo avanzar la participación en el continente más desigual de todos?, Revista de Administração Pública, 41, (3), 537-581. Recuperado de http://www.scielo.br/pdf/rap/v41n3/ a08v41n3.pdf

Latinobarómetro (2016). Informe Latinobarómetro 2016, Santiago de Chile, Chile, Corporación Latinobarómetro. Recuperado de http://www. latinobarometro.org/latNewsShow.jsp

Llistar Bosch, D. (2009). Anticooperación. Interferencias Globales Norte-Sur. Los Problemas del Sur no se resuelven con más ayuda internacional, Barcelona, España, Icaria.

Mignolo, W (2005). La colonialidad a lo largo y a lo ancho: el hemisferio occidental en el horizonte colonial de la modernidad en E. Lander (comp.). La colonialidad del saber: eurocentrismo y ciencias sociales. Perspectivas Latinoamericanas. Buenos Aires, Argentina, Clacso,

Moore, B. (1966). Social Origins of Dictatorship and Democracy: Lord and Peasant in the Making of the Modern World. Boston, EE.UU., Beacon Press.

Navarro, Z. (1998) La democracia afirmativa y el desarrollo redistributivo: el caso del presupuesto participativo en Porto Alegre, Brasil (1989-98). En CALDERA, A.; JARQUÍN, E. Programas sociales, pobreza y participación ciudadana. BID.

OEA y PNUD (2010). Nuestra Democracia. México D.F., Fondo de Cultura Económica.

Omar, S. M. (2008). Los estudios post-coloniales. Una introducción crítica, Castelló, España, Servei de Publicacions de la Universitat Jaume I.

Santos, B. de S. (2004). Democracia de Alta Intensidad. Apuntes para democratizar la democracia. La Paz, Bolivia. Corte Nacional Electoral.

Svampa, M. (2017). Cuatro claves para leer América Latina. Revista Nueva Sociedad, 168, 50-64. Recuperado de http://nuso.org/articulo/cuatroclaves-para-leer-america-latina/ 